\title{
PACIENTE EM TERAPIA DIALÍTICA X DOENÇA PERIODONTAL: RELATO DE CASO CLÍNICO
}

Caroline de Souza Gomes BRANDÃO; Talita Farias MIKSZA; Rafaela Casagrande FIGLARZ

A insuficiência renal crônica exige um protocolo eficaz, pois esses pacientes são mais susceptíveis a hemorragias e doenças periodontais. A perda da função renal dificulta o metabolismo do cálcio e do fósforo diminuindo a capacidade de ativação da vitamina $D$, provocando hipocalcemia e hiperparatireoidismo. A reposição de cálcio é feita através da administração de cerca de 10 comprimidos de carbonato de cálcio diária ocasionando a formação de uma camada de cálculo sobre os dentes dos pacientes que apresentam uma higiene bucal deficiente. Esse trabalho visa elucidar sobre a intervenção periodontal em paciente dialítico através de relato de caso clinico. R. F, 28 anos, fumante, relatou fazer hemodiálise, tomar medicações antihipertensivas, diuréticas, para repor cálcio e anemia. Fez cirurgia para confecção da fístula arteriovenosa e bexiga (pressão arterial no dia do exame era de 100/60 $\mathrm{mmHg}$, seus batimentos 63/min). Após exame clínico detalhado e radiográfico foi realizado o tratamento levando em consideração sua condição sistêmica. Foi realizado adequação do meio bucal, confecção de próteses removíveis provisórias, restabelecendo a saúde bucal do paciente, melhorando seu estado sistêmico e recuperando sua auto-estima. 